\title{
A COMPARATIVE ANALYSIS OF TEXT DIFFICULTY IN SLOVAK AND CANADIAN SCIENCE TEXTBOOKS
}

\begin{abstract}
One of the main purposes of textbooks is the mediation of educational content to students. The factual accuracy of information, as well as the clarity of the text for students plays a crucial role in this aspect. The inadequate text difficulty can complicate students' learning. Comparing different approaches to the text in textbooks, considering the objectives of education, represents key knowledge for teaching materials innovation. This research was therefore focused on the comparison of the Slovak and Canadian science textbooks for lower secondary education. The methodology for assessing text difficulty according to Nestler, Prucha and Pluskal was used for this purpose. The samples of text from the textbooks for 6th and 8th grade of lower-secondary school were assessed. It was found that the text in Slovak textbooks is significantly more difficult. While from the syntactic difficulty point of view differences were rather partial, the significant differences were found in the semantic difficulty of the text. The Slovak textbooks are burdened with an excessive number of professional terms. Considering the results in measuring scientific literacy, this approach to the text in the Slovak textbooks is not effective. The results obtained are therefore an incentive to revise used educational materials.
\end{abstract}

Keywords: science textbooks, text difficulty, science education, lower secondary schools

\section{Introduction}

Science education meets several challenges nowadays. These challenges mean the fast increasing science knowledge, including the adoption of new methods and approaches, what leads to the need of educational content reassessment, taking into account knowledge obsolescence, as well as the change of thinking about science education [1]. The second area is the need to develop students' competences transferable to extracurricular environment and their future life [2]. That is why it is necessary to continuously revise curricular documents, as well as key elements directing education. The same is true in case of its specific transformation the students encounter, thus for the textbooks. The importance of focused attention to these materials is demonstrated by growing international research interest in the field of science textbooks [3].

Textbooks fulfill a number of functions in the educational process, which are realized through the included structural components $[4,5]$. One of the key functions of the textbook is to mediate the educational content to students. In this sense, the educational text is especially important. Its concept and quality of elaboration determines the possibilities of

\footnotetext{
${ }^{1}$ Základná škola s materskou školou, Atómová 1, 91701 Trnava, Slovakia, email: z.benickova@ gmail.com

${ }^{2}$ Faculty of Education, Charles University, Magdalény Rettigové 4, 11639 Prague 1, Czech Republic, phone +420737471705, ORCID: 0000-0002-7619-9891

${ }^{3}$ Faculty of Education, Trnava University in Trnava, P.O. Box 9, 91843 Trnava, Slovakia, email: lubomir.held@truni.sk

* Corresponding author: karel.vojir@pedf.cuni.cz
} 
its use. It is therefore crucial to deal not only with factual accuracy, but also other characteristics involving students' work with the text $[6,7]$. The mapping of text difficulty in textbooks seems to be one of relevant approaches [6,7]. Evidence-based comparison of text in the textbooks can be a useful tool on an open market with textbooks, which is often saturated and not transparent. Objective parameters are very useful for orientation in such a confusing situation. With regard to the need to have research knowledge for the possibility of relevant and evidence-based material innovations, it plays a significant role also in countries where the textbook market almost does not exist, or textbooks publishing is centralised. This is the situation in Slovakia. For now, it concerns only partial actions to characterise Slovak chemistry textbooks from the point of view of text specifics [8].

A thorough knowledge of used educational materials can help in understanding educational outcomes thanks to its potential implementation and shows possible limits and strengths of further innovation in the field of education. The most used indicator for assessing the achievement of education goals internationally present PISA findings focused on measuring scientific literacy. Slovakia shows deteriorating results in the long run in the field of scientific literacy. By contrast, Canada has been ranked among the best performing countries $[9,10]$ not just in terms of scientific literacy, but also in terms of reading literacy. Aspects of these two literacies are mutually connected when reading science text. Curriculum in countries with good results in education can be taken as an inspiration for educational systems in countries with lower results. The research presented in this article is therefore focused on the comparison of the Slovak and Canadian textbooks from the point of view of text.

\section{Theoretical background}

The textbook is often referred to as the main didactic aid [11], which is used practically worldwide. The purpose of the textbook is to fulfil a number of functions, as the organization and structuring of educational content, regulation and integration of education, motivation, presentation of teaching methods, etc. Since it is an aid primarily intended for students, the transmission of information remains its key role. Education process in general is largely conditioned by effective communication [12]. So, if a textbook is to fulfil its function as a medium, which enables the transmission of information to students, it is necessary to emphasise the quality of the text contained therein not only from the point of view of its content, despite its suitability and factual accuracy are an essential factor in education. For the possibility of effective transmission of information, it is necessary to consider the understanding of the text, which is influenced by a student and his/her previous knowledge and skills on the one hand and the material itself and its difficulty on the other hand [13]. Different parameters in textbooks indicate its readability in general [14], which includes, inter alia, the adequacy of the text, its internal consistency or semantic and syntactic difficulty.

Difficulty of the text can be determined by estimating made by experts or text users (teachers, students). However, text assessment by respective actors is to a significant extent burdened by their subjective perceptions. That is why an approach based on objective text parameters is used in research and is independent from reviewers or students. Those parameters are usually sentence length, sentence complexity, the number and difficulty of terms, the rate of terms repeatability, etc. Thus, text difficulty is for a reader impacted by lexical, as well as syntax factors. These are included into so called formula for calculating text difficulty. Individual indicators are included into so called formula, where text data are 
inserted and based on it text difficulty is calculated. The broadly available is Nestler formula which is used also by Prucha in its modified form [15].

As stated by Wellington and Osborne [16], language is one of the greatest barriers for most students in study of science. Scientific text has a lot of specifics. In addition to specific technical terms, these specifics include signs or features which have the role of words (professional terms) but its expression is fundamentally different comparing to general texts or texts from other fields. It was also confirmed by Hoang [17] in his research of language characteristics in biology textbooks. High specificity of the language used in science textbooks including, inter alia, important focus on physical and relational processes, or high lexical density lead to language alienation for students [17].

Transmission of the field information by means of text is necessarily linked to its functional understanding. Scientific text understanding can be thus perceived as one of the core elements of scientific literacy [18]. Despite its essential character, it concerns an unexplored area in the international research field focused on science textbooks [3]. The importance of the issue clearly indicates that the most cited publication in this field is focused on language specifics [19]. Similarly, there is the increase of publications in impacted journals addressing texts in the science textbooks in the last years [3].

With regard to the linguistic characteristics of the text, considerable research attention in the field of science textbooks was paid to the understanding of the text by students $[20,21]$, used lexical relations [22], the comparison of language specifics in various fields $[23,24]$, term load $[25,26]$ and text readability, including semantic and syntactic difficulty of the text [27-29].

When we look at research carried out internationally, we do not find a unifying factor in the form of a research method (the same "formula" for the calculation of reviewed text difficulty). In particular for English written texts, automated measuring tools were established in order to assess text cohesion and coherence [13]. Such tools are not available for most languages, also for the Slovak language, and analysis is made directly by researchers [7]. The use of different methodologies does not allow a direct comparison of the characteristics of the text. Targeted comparative analysis therefore proves to be a suitable next step in research in this field. Although some research shows cultural differences in educational content [30] or selection of illustrations [31, 32] in science textbooks, differences in the educational text characteristics of textbooks aimed at integrated science versus particular scientific disciplines have not yet been addressed.

\section{Aims}

The text in textbooks is one of its main characteristics, which determines the possibility of using them in education and thus may impact students' results. While the English-language Canadian textbooks for ISCED 2 present science in an integrated form, natural sciences in Slovakia are taught separately, thus the textbooks used for this purpose are focused only on one science discipline (biology, physics, chemistry). There is the reason to assume that also text character can be different. In the context of considering the further direction of (not only science) education, it is desirable to gain empirical insight into the differences of these approaches from different perspectives. The aim of this research was to compare Slovak and Canadian textbooks (i.e. textbooks with significantly different conception) in terms of text difficulty. This aim has been specified in more details by research questions: 
- What is the syntactic and semantic text difficulty in selected Slovak and Canadian science textbooks (ISCED 2)?

- What is the density of professional information in selected Slovak and Canadian science textbooks (ISCED 2)?

\section{Methods}

To answer the research questions, the analysis of selected Canadian and Slovak science textbooks was carried out in the light of the semantic and syntactic difficulty of the explanatory text. For this purpose, the established methodology of Nestler, further developed by Prucha and modified by Pluskal was used [15]. This methodology was also used with regard to the possibility of comparing the results with research conducted in the Czechia $[6,7]$. The textbooks for 6th and 8th grade were chosen to compare the differences in the science textbooks in lower secondary education. Text sections, which were analysed, had been chosen from selected textbooks in compliance with the methodology. The coefficients describing the difficulty of the text have been calculated on the basis of quantified number of terms and the structure of sentences. Finally, these coefficients were compared.

\section{Analysed textbooks}

The English written textbooks used in the province of Ontario and the valid Slovak textbooks were analysed. The textbooks, which from the publishing point of view come from approximately the same period, were compared (published around 2000). The education systems in Slovakia and Canada are conceptually different which is then reflected also in particular textbooks. While in Slovakia, science education (at the secondary level of education) is divided into individual subjects based on the structure of individual natural sciences (such as i.e. chemistry, physics, etc.), the Canadian curriculum of natural science is more thematically integrated. Since the nature of the text can vary in different educational fields [24], for the possibility of comparison, all textbooks intended for the given grades focused on scientific educational content were included in the research sample (Table 1).

Ten samples of texts with a minimum length of 200 words were selected within each of the compared grades for each country. Due to the different structure of the textbooks and the content itself, it was not possible to choose among the textbooks directly comparable samples of the text, which would allow comparison at the level of elaboration of topics. However, the samples of texts from the Slovakian and Canadian textbooks have been selected so that the samples within each grade under comparison were similar considering biological, physical, and chemical content.

Five text samples were selected from each of the Slovak textbooks for the sixth grade. Ten text samples were selected from the textbook Science Everywhere 6. Similarly, we selected ten samples of the text from the Slovak textbooks of physics, natural science, and chemistry for the eighth grade. We selected three samples from the physics textbook for the eighth grade, three samples from the natural science textbook for the eighth grade, and four samples from the chemistry textbook for the eighth grade. We also selected a total of ten text samples from four Canadian textbooks that cover the science subject in the eighth grade. We selected three samples from the textbook Force, Work and Energy, two samples 
from the textbook Characteristics and Classification of Living Things, three samples from the textbook Properties of Matter and two samples from the textbook Nature of Science.

Table 1

Overview of analysed textbooks

\begin{tabular}{|c|c|c|c|c|c|}
\hline Grade & Country & Authors & Textbook title & Publishing house & $\begin{array}{c}\text { Year of } \\
\text { publishing }\end{array}$ \\
\hline \multirow{3}{*}{6} & \multirow{2}{*}{ SVK } & Janovic J. & Fyzika 6/A [Physics 6/A] & SPN & 2002 \\
\hline & & Hantabalova I. & Prirodopis 6 [Biology 6] & SPN & 2002 \\
\hline & CAN & $\begin{array}{l}\text { Asselstine L. } \\
\text { Peturson R. }\end{array}$ & Science Everywhere 6 & $\begin{array}{c}\text { Hartcourt Brace } \\
\text { Canada }\end{array}$ & 1999 \\
\hline \multirow{7}{*}{8} & \multirow{3}{*}{ SVK } & Kolarova R. & Fyzika 8/A [Physics 8/A] & SPN & 2001 \\
\hline & & Aubrechtova R. & Prirodopis 8 [Biology 8] & SPN & 2000 \\
\hline & & Adamkovic E. & Chemia 8 [Chemistry 8 ] & SPN & 2000 \\
\hline & \multirow{4}{*}{$\mathrm{CAN}$} & Wiese J. & Force, Work, and Energy & $\begin{array}{l}\text { ITP Nelson } \\
\text { Canada }\end{array}$ & 1997 \\
\hline & & Ritter B. & $\begin{array}{c}\text { Characteristics and Classification of } \\
\text { Living Things }\end{array}$ & $\begin{array}{l}\text { ITP Nelson } \\
\text { Canada }\end{array}$ & 1997 \\
\hline & & Gibb T. & Properties of Matter & $\begin{array}{l}\text { ITP Nelson } \\
\text { Canada }\end{array}$ & 1997 \\
\hline & & $\begin{array}{l}\text { Ritter B. } \\
\text { Wiese J. }\end{array}$ & The Nature of Science & $\begin{array}{l}\text { ITP Nelson } \\
\text { Canada }\end{array}$ & 1997 \\
\hline
\end{tabular}

The samples proportionally covered various topics. They were not selected from the first pages, where atypical text usually occurs. Each sample formed a coherent text. A word we considered to be any word, numeric, or symbolic expression (including abbreviations) that is separated in the text by graphic spaces or interpunction marks. Commonly used symbols were also counted as words, as it is stated by Prucha [15].

\section{Analysis of textbooks' didactic equipment}

The specific procedure of the methodology for determining the difficulty of the text according to Nestler-Prucha-Pluskal [15] consists in several steps. In the selected text samples we counted: the total number of words $(N)$, sentences (any sequence of words beginning with a capital letter and ending with a dot or graphic symbol representing it (?,!,etc.) $(S)$ and vocabs in active form $(V)$. In addition, all the nouns were calculated, including nominalized adjectives - total number of terms $(T)$. Identified terms have been classified in five different categories: general terms $\left(T_{1}\right)$, professional terms $\left(T_{2}\right)$, repeated terms $\left(T_{3}\right)$, quantitative terms $\left(T_{4}\right)$, geographical terms $\left(T_{5}\right)$. Found values have been processed and the coefficient of text difficulty has been calculated on its basis:

A) Syntactic text difficulty $\left(D_{s t}\right)$

$$
D_{s t}=0.1 \cdot \frac{N^{2}}{V \cdot S}
$$

B) Semantic text difficulty $\left(D_{s m}\right)$

$$
D_{s m}=100 \cdot \frac{T}{N} \cdot \frac{T_{1}+3 \cdot T_{2}+2 \cdot T_{3}+2 \cdot T_{4}+T_{5}}{N}
$$

C) Total text difficulty $(D)$

$$
D=D_{s t}+D_{s m}
$$


D) Density coefficients of professional information $(i, h)$.

$$
\begin{aligned}
& i=100 \cdot \frac{T_{2}+T_{3}+T_{4}}{N} \\
& h=100 \cdot \frac{T_{2}+T_{3}+T_{4}}{T}
\end{aligned}
$$

In the last step of the analysis, the values found were interpreted and the samples of the Canadian and Slovak textbooks were compared.

\section{Findings and discussion}

We found a certain difference in the syntactic difficulty of the texts in the Canadian and Slovak science textbooks for the 6th grade of elementary school (Fig. 1). The Canadian textbook Science Everywhere 6 seems to be more syntactically difficult. The value of syntactic difficulty is 10.02 . The syntactic difficulty of the Slovak textbooks for the 6th grade is 7.44. In Canadian textbooks there is only a small difference in the syntactic difficulty of the text in 6th and 8th grade. Only slightly higher value 11.99 was found in the textbooks for the 8th grade. Compared to that, in the case of Slovak textbooks, a high increase of syntactic difficulty between grades to the value 12.71 was found. Therefore, it can be stated that the texts in the Canadian textbooks are similarly syntactically difficult as Slovak textbooks, but its value does not change dramatically between grades, as it is in case of the Slovak textbooks for the 6th and 8th grade.

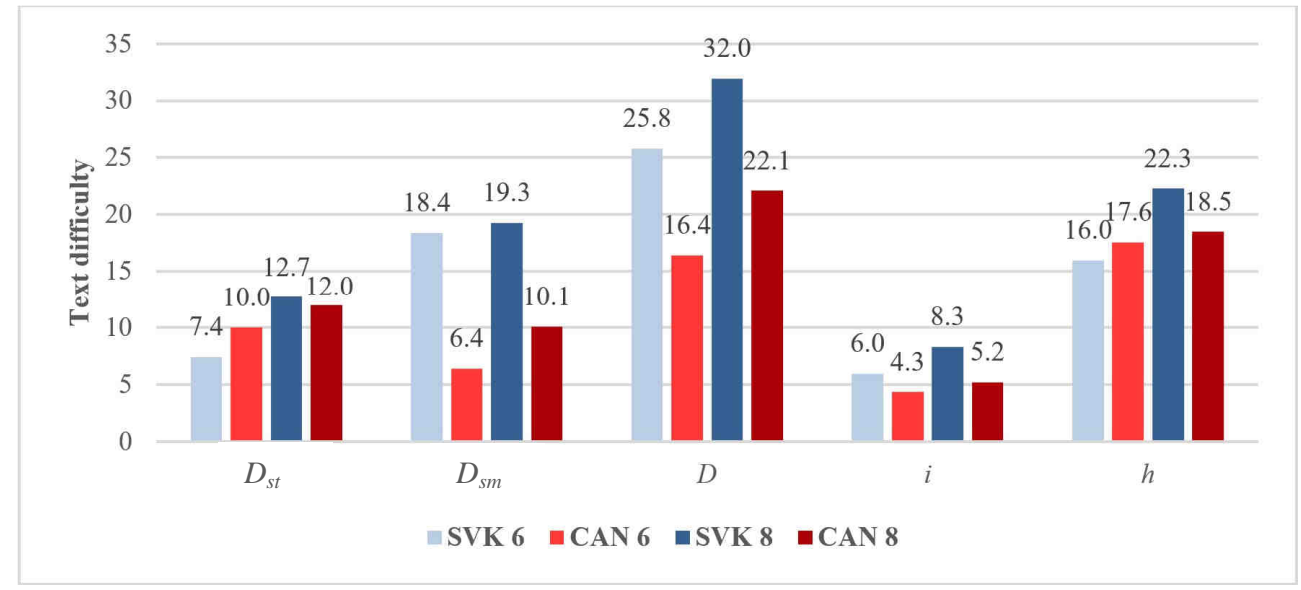

Fig. 1. The text difficulty in the Canadian (CAN) and Slovak (SVK) science textbooks for the 6th and 8th grade of lower-secondary school

We found the significant differences in semantic difficulty between the Canadian and Slovak science textbooks for the 6th and 8th grade of lower-secondary school. Semantic difficulty of the text in the Slovak textbooks for the 6th grade is 18.37 , however in the Canadian textbooks it is only 6.40. In the case of Slovak textbooks, it is almost three times higher. Semantic difficulty of the text in the Slovak textbooks for the 8th grade is 19.26 and semantic text difficulty in the Canadian textbooks is 10.10 . Even in the case of this grade, Slovak textbooks are significantly more semantically difficult. 
Although the Canadian textbook for the 6th grade is more semantically difficult, the high difference in semantic difficulty causes that the total text difficulty of the Slovak textbooks for the 6th and also for the 8th grade is significantly higher than in the case of Canadian textbooks. Total text difficulty in the Slovak science textbooks for the 6th grade is 25.81 and in the Canadian textbook it is 16.42 , what is a 9 points difference. Total text difficulty in the Slovak science textbooks for the 8th grade is 31.97 and in the Canadian textbook it is 22.09 , what is a 10 points difference. As these findings show, the differences in semantic and, as a result, total difficulty of the text in Canadian and Slovak textbooks are considerable.

Coefficient $i$, which expresses the proportion of terms carrying professional information in the total number of words $N$, is higher in the Slovak science textbooks for the 6th and 8th grade comparing to the Canadian textbooks. A high increase in this coefficient was found in the Slovak textbooks for the 6th and 8th grade (from the value 5.98 to 8.32). A small increase between grades was also found in the case of Canadian textbooks (from the value 4.34 to 5.20). On the other hand, there is a slight deviation in coefficient $h$, expressing the proportion of terms carrying professional information in the total number of terms $T$, in the Canadian and Slovak textbooks. The coefficient $h$ in the textbooks for the 6 th grade differs by less than two points, this can be considered negligible. Very high value of density of professional information in terms was found in the Slovak textbooks for the eighth grade. This is significantly higher than the value of the Canadian textbooks, at the same time, a high increase was observed compared to the textbooks for the 6th grade. Although the textbooks addressed only two grades, for the Slovak textbooks, there is a significantly higher burden on students with professional terms at the end of lower secondary education. In the Canadian textbooks, the density of professional terms is almost balanced between the grades.

Similarly high values of total difficulty of the text, as it is in case of the Slovak textbooks, as well as the high density of professional information was also found in research of biology and chemistry textbooks in the Czech Republic [6, 7, 27, 33]. Even significantly higher values were found in the Czech textbooks in case of professional terms. These similarities in the approach to the structure of the science educational content based on a large amount of professional information reflected in the educational text can be attributed to the common development of the curriculum in previous times.

The high difficulty of scientific text burdened with professional information results in a lack of understandability for students [16]. The nature of the text found in the Slovak science textbooks may thus be one of the reasons for the significantly worse results that Slovak students achieve in the measurements of scientific literacy compared to the Canadian ones [10]. If the text in textbooks is too difficult for students, they are likely to tend to other sources, such as notes prepared by the teacher. Thanks to this, students do not work with a comprehensive scientific text, so there is no development of related skills. This aspect is closely linked to the development of functional reading literacy, which cannot be associated only with the ability to read fluently and read everything. At the same time, the scientific text carries several specifics, such as specifically subject language structures, terms and forms of expression, e.g. marks and formulas [34]. The ability to understand the scientific text is therefore an integral part of scientific literacy development [1]. At the same time, textbook in this area become a dysfunctional learning aid, as it cannot adequately transfer the field information to students [14]. 
Disproportionate difficulty of scientific explanatory text, which is too difficult for students to understand, together with the overwhelming professional terms that must be memorized, can lead to low popularity of science among students in Slovakia and insufficient interest in their studies [35].

\section{Results limits}

There is lack of information related to the use of used methodology of textbooks assessment comparing to the textbooks in various languages, eventually different cultural or at least didactical background. Thus, the results can be limited by this factor. The phonetics of the written Slovak language is relatively easy. On the other hand, the graphical and phonetic feature of English is different. The Canadian students, contrarily to the Slovak ones, must understand the meaning of words. Despite these differences, according to students' skills and language specifics, the significant differences in including professional terms show a different approach to scientific text structure, what also confirms the importance of the study results.

Although an established methodology used in number of researchers [6, 7, 27, 36] was followed, the choice of text samples for analysis can be a possible limit. Bearing in mind the limit of partial deviations, emphasis is placed on the observed trends in the identified text difficulty in the textbooks.

\section{Conclusion}

In this research educational texts used for the same age categories of students in compulsory lower secondary science education were compared. It was found that the science textbooks used in Slovakia and Canada in 2000 and later show only small differences in syntactic difficulty. The differences can be conceptual - in lower grades the values are more favourable. It can also result from stylistic differences between the two languages. On the contrary, in the semantic difficulty of the text the considerable differences were found. The Slovak textbooks are semantically much more difficult comparing to the Canadian ones. This, of course, is reflected in the total difficulty of educational text. This difference is mainly caused by significantly higher proportions of professional terms in the Slovak textbooks. Decision of the authors about the inclusion of more professional terms cannot attribute to language specifics. This shows a different conception in the creation of the textbook and the requirements placed on students in the study of sciences.

If we accept, at least to some extent, the methodology used, including the available sample of textbooks, we can express a final argument that difficult textbooks may represent a factor which negatively impacts the level of students' scientific literacy. This problem is of course more complex, and we find our results as a small contribution to make it more visible. At the same time, it is the basis for curriculum makers and authors of new textbooks and other educational materials.

\section{Acknowledgements}

The work on this paper was supported by the Slovak Research and Development Agency, contract No. APVV-14-0070. 


\section{References}

[1] OECD. PISA 2018 Assessment and Analytical Framework; 2019. DOI: 10.1787/b25efab8-en.

[2] Official J EU. 2018;61:1-13. Available from: https://eur-lex.europa.eu/legal-content/EN/TXT/ PDF/?uri=CELEX:32018H0604(01)\&rid=7.

[3] Vojîr K, Rusek M. Int J Sci Educ. 2019;41:1496-516. DOI: 10.1080/09500693.2019.1613584.

[4] Rusek M, Vojiŕr K, Šubová Š. Chem Didact Ecol Metrol. 2020;25:69-77. DOI: 10.2478/cdem-2020-0004.

[5] Karásková N, Doležal R, Maltsevskaya N, Kolář K. Chem Didact Ecol Metrol. 2019;24:61-76. DOI: 10.2478/cdem-2019-0005.

[6] Rusek M, Stárková D, Metelková I, Beneš P. Chem Listy. 2016;110:953-8. WOS: 000390899900017.

[7] Rusek M, Vojír K. Chem Edu Res Prac. 2019;20:85-94. DOI: 10.1039/c8rp00141c.

[8] Kmet'ová J. Chem listy. 2004;98:557-8. Available from: http://www.chemickelisty.cz/ojs3/index.php/chemicke-listy/article/view/3300/3262.

[9] OECD. Pathways to Success: How knowledge and skills at age 15 shape future lives in Canada; 2010. Available from: https://www.oecd-ilibrary.org/docserver/9789264081925-en.pdf?expires=1614419786\& $\mathrm{id}=\mathrm{id} \&$ accname $=$ guest $\&$ checksum $=91593$ BF780AE1104F5529B5DC984319D.

[10] OECD. PISA 2018 Results: Combined executive summaries; 2019. Available from: https://www.oecd.org/pisa/Combined_Executive_Summaries_PISA_2018.pdf.

[11] Valverde GA, Bianchi LJ, Wolfe RG, Schmidt WH, Houang RT. According to the Book: Using TIMSS to Investigate the Translation of Policy into Practice Through the World of Textbooks. Dordrecht: Springer Science \& Business Media; 2002. ISBN: 9781402010347.

[12] Aydin S, Sinha S, Izci K. Eurasia J Mathematics Sci Technol Education. 2014;10:383-93. DOI: 10.12973/eurasia.2014.1060a.

[13] Pyburn DT, Pazicni S. J Chem Education. 2014;91:778-83. DOI: 10.1021/ed500006u.

[14] Mikk J. Edu Stud. 2008;34:119-27. DOI: 10.1080/03055690701811164.

[15] Průcha J. Učebnice: Teorie a analýzy edukačního média [Textbook: Theory and analysis of educational medium]. Brno: Paido; 1998. ISBN: 8085931494.

[16] Wellington J, Osborne J. Language and Literacy in Science Education. London: Open University Press; 2001. ISBN: 0335205984.

[17] Hoang VV. Ling Hum Sci. 2018;14:1-35. DOI: 10.1558/lhs.31751.

[18] Nemeth JM. J Chem Edu. 2006;83:592. DOI: 10.1021/ed083p592.

[19] Biber D, Conrad S, Cortes V. App Ling. 2004;25:371-405. DOI: 10.1093/applin/25.3.371.

[20] Smith BL, Holliday WG, Austin HW. J Res Sci Teach. 2010;47:363-79. DOI: 10.1002/tea.20378.

[21] Gericke NM, Hagberg M, Jorde D. Res Sci Edu. 2013;43:755-80. DOI: 10.1007/s11165-012-9288-z.

[22] Ibanez R, Moncada F, Carcamo B. Disc Proc. 2019;56:764-85. DOI: 10.1080/0163853x.2019.1565278.

[23] Green C. Ling Edu. 2019;53. DOI: 10.1016/j.linged.2019.100748.

[24] Fitzgerald WJ, Elmore J, Relyea JE, Stenner AJ. J Edu Psy. 2020;112:855-79. DOI: 10.1037/edu0000386.

[25] Hsu WH. Eng Spec Purp. 2014;33:54-65. DOI: 10.1016/j.esp.2013.07.001.

[26] Fitzgerald WJ, Elmore J, Kung M, Stenner AJ. Read Res Quart. 2017;52:417-42. DOI: 10.1002/rrq.184.

[27] Hrabí L. New Edu Rev. 2010;22:143-8. WOS: 000294162000012.

[28] Bansiong AJ. Cogent Edu. 2019;6. DOI: 10.1080/2331186x.2019.1706395.

[29] Gul S, Ozay Kose E, Diken EH. Cukurova Univ Faculty Education J. 2020;49:1-27. DOI: 10.14812 /cufej.466481.

[30] Calado FM, Scharfenberg FJ, Bogner FX. Int J Sci Edu Part B Comm Pub Eng. 2018;8:266-86. DOI: 10.1080/21548455.2018.1486051.

[31] Carvalho GS, Tracana RB, Skujiene G, Turcinaviciene J. Int J Sci Edu. 2011;33:2587-610. DOI: 10.1080/09500693.2011.556831.

[32] Ge YP, Unsworth L, Wang KH, Chang HP. Res Sci Edu. 2018;48:1409-31. DOI: 10.1007/s11165-016-9608-9.

[33] Hrabí L. Náročnost textu v učebnicích přírodopisu [Difficulty of the text in biology textbooks]. In: Maňák J, Knecht P, editors. Hodnocení učebnic [Evaluation of textbooks]. Brno: Paido; 2007. ISBN: 9788073151485.

[34] Markic S, Childs PE. Chem Edu Res Prac. 2016;17:434-8. DOI: 10.1039/C6RP90006B.

[35] Veselský M, Hrubišková H. Ped orien. 2014;19:45-64. Available from: https://Js.muni.cz/pedor/article/view/1259.

[36] Beneš P, Janoušek R, Novotný M. Pedagogika. 2009;59:291-7. Available from: https://pages.pedf.cuni.cz/pedagogika/?p=1000. 